\title{
Ethical Implications of Mental Health Stigma: Primary Health Care Providers' Perspectives
}

\author{
Sawsan Abuhammad ${ }^{1} \&$ Heyam Dalky $^{1}$ \\ ${ }^{1}$ School of Nursing, Jordan University of Science and Technology, Irbid, Jordan \\ Correspondence: Sawsan Abuhammad, School of Nursing, Jordan University of Science and Technology, Irbid, \\ Jordan. E-mail: Shabuhammad@just.edu.jo
}

Received: August 1, 2018 Accepted: October 11, 2019 Online Published: October 15, 2019

doi:10.5539/gjhs.v11n12p165 URL: https://doi.org/10.5539/gjhs.v11n12p165

\begin{abstract}
Stigma towards mental illness is a widespread phenomenon not just in the developing world, but also in developed countries. Unfortunately, this stigma is not only restricted to the general population, but is also prevalent among professional health care providers. Research from developing countries is scarce. Thus, the aim of this paper was to explore health care providers' attitudes toward mental illness stigma in the primary health care settings. The review sheds light on the ethical implications of mental health stigma as perceived by primary health care providers, and the proposed recommendations for responsible conduct of research and policy initiative in the context of mental health research. Utilizing CINAHL, Medline and Scopus electronic data bases, results are reported for the 41 studies that are grouped according to being from USA, Europe, Australia, Africa, and Asia and Arab World. The results from this review confirmed that stigma associated with mental illness have many ethical implications in the context of research including use of consent form, fair treatment, and good respect for individual rights concerning treatment choices. To counter stigma and prevent the ethical implications of such stigma, interventions in the form of awareness and training programs would be the best way to minimize and stop it. Further, govermnetal and political are needed to initiate a national code of ethics for mental health research in their respective coutries.
\end{abstract}

Keywords: attitudes, stigma, mental illness, health care providers, implications

\section{Introduction}

Mental illness is one of the most stigmatized conditions worldwide. The Surgeon General's 1999 report on mental health stated that to improve mental health and mental health care, stigma must be addressed. The origin of stigma is rooted in the literature. Goffman (1963) thought of stigma as an element that is "deeply discrediting." According to Goffman, stigmatized persons are regarded as being of less value and "spoiled" by the stigmatizing effects of three conditions: "abominations" of the body, such as physical deformities; "tribal identities," such as ethnicity, sex, o religion; and "blemishes of individual character," such as mental disorders or unemployment (Goffman, 1963).

Stigma is a reality for people with mental illness, and feeling stigmatized is one of the greatest barrier to complete and satisfying life (Dalky, 2012a, 2012b; Sartorius, 2012). Further, society feels uncomfortable about mental illness. It is not seen like other illnesses such as heart disease and cancer. Due to inaccuracies and misunderstandings, people have been led to believe that an individual with mental illness has a week character or is certainly dangerous. If a friend or colleagues at work announces that they need time off for cancer treatment or because of a broken leg, they are shown empathy and support. On the other hand, if the person asks for time off to deal with a mental illness, they risk rejections, humiliation, and possibility even the loss of their job.

\subsection{Attitudes Towards Mental Health Stigma}

Stigma towards mentally ill patients is a widespread phenomenon not just in the developing world, but also in developed countries. Unfortunately, this stigma is not only restricted to the general population, but is also prevalent among professional health care providers (Mishra et al., 2014; Sartorius, 2012). Many mentally ill patients experience stigmatization that leads to discriminatory behaviors that discourage them from seeking help from health care professionals. The literature shows growing evidence those mentally ill patients' needs are overlooked by general/primary health care providers and non psychiatric physicians. Cultural variations regarding knowledge 
and awareness of mental health problems also impact treatment of those suffering from psychiatric conditions (Abuhammad, Hatamleh, Howard, \& Ahmad, 2018).

Research from developing countries is scarce. For example; in Jordan, few studies were identified tackling stigma of mental illness; however, few if none are found about primary health care providers' perspectives and attitudes towards providing care to people with mental illness. The aim of this paper is to synthesize the literature related to attitudes toward patients with mental illness with examples from various countries around the world. This literature focused on elucidating the remedial methods suggested by researchers to counteract stigma associated with mental illnesses. Further, the review will shed the light on the implications encountered by mental health stigma as perceived by primary health care providers, and the proposed recommendations for responsible conduct of research (RCR) and policy initiative in the context of mental health research.

\section{Method}

The literature search was conducted using the following electronic databases: Medline, CINAHL, and Scopus. The following search terms were used: stigma AND mental illness; AND primary care setting; negative attitude AND mental illnesses AND primary care setting; prejudice AND mental illness AND primary care sets. The scope of the search was later expanded to include a reference list of related articles, including dissertations, theses, conference proceedings, editorials, opinions and theoretical articles. Articles were screened with the overall goal of identifying data-based studies that focused specifically on the relationship between the two concepts: mental illness AND primary care setting and stigma. Inclusion criteria were as follows: 1) published in English, and 2) no limitation on publication date. Articles were excluded 1) if they did not focus on the main concepts of this review (mental illness AND primary care setting and stigma), 2) if they focused only on the physiological aspects of mental illness AND primary care setting and stigma, or 3) if they included other health care providers.

Each abstract was thoroughly evaluated since the title often was insufficient to judge the relevancy of a given study for this review. If the abstract was relevant to the focus of this review, the article was transferred to the data-management software Endnote. Out of 60 articles, 22 met the inclusion criteria. The Prisma table Figure (1) at the end of this paper provides a detailed description of the articles that are included in this literature review. Each article was printed, and data were assessed according to the variables addressed so that comparing studies across each outcome was feasible. The themes in the results section were determined according to how the results of the relationship between mental illness AND primary care setting AND stigma were categorized.

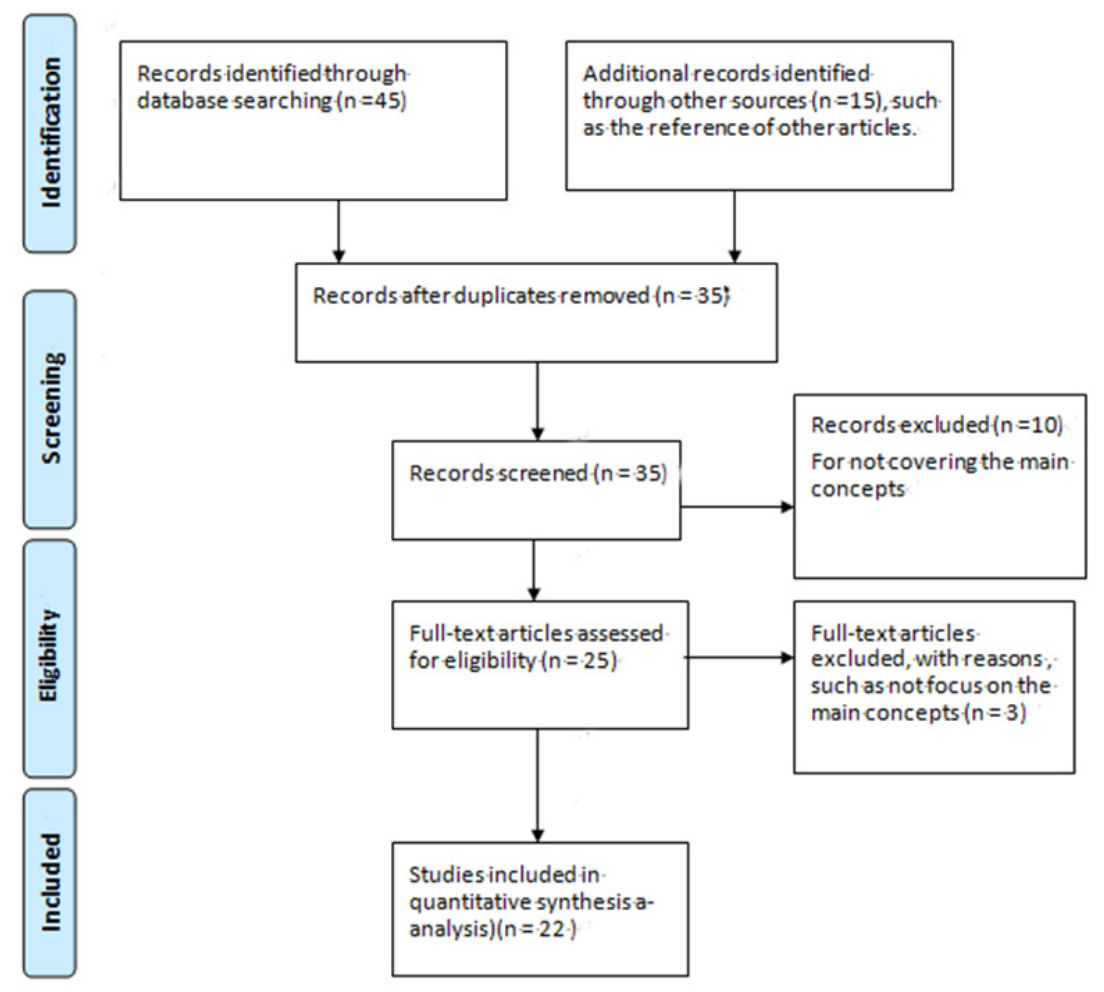

Figure 1. PRISMA for Mental Health Stigma and Primary care setting 


\section{Results of the Literature Review}

The results of the literature review are displayed. The four themes are as follows: 1) lack of training and knowledge, 2) Lack or poor Cooperation Between General Physicians and Psychiatrists, 3) Lack of Exposure to Mental Ill Patients, and 4) Consider not part of job duties. The last section revealed the proposed ethical and political implications for RCR for mental health stigma in primary health care settings in Jordan.

\subsection{Lack of Training and Knowledge}

One reason that may cause primary care provider to hold stigma to mental health patiens is lack of training and poor knowledge about mental illnesses. Blount and Miller (2009) listed and described the challenges as a workforce crisis in integrated primary care. These authors contended that general graduate training programs for health care providers do not prepare students adequately enough to assist mental health patients. The training is also not sufficient enough to be adapted for different cultures and types of mental health patients. They suggest better and more advanced training and adjustments to fit the market needs. Another study of Kravitz and colleagues (2006), in RCT included approximately 150 primary health care provider participants; the study assesses patients with mental health concerns. These patients suffered from depression or maladjustment disorders and needed either brand specific or generic medications. The results of this study were that only $36 \%$ of patients were referred by general primary care providers to mental health facilities (Kravitz et al., 2006). The study also indicates that primary health care providers that were exposed to mental health education or training were more likely to refer their patients to mental health facilities. The patients were referred to psychiatrists, social workers, or counselors (Kravitz et al., 2006).

In general, studies have shown those healthcare providers' display negative attitudes towards people with mental disorders. This is also a phenomenon in both Europe and Australia related to lack of training. In Scotland, Crabtree and Mack (2010) conducted a study to assess nurses' attitudes towards mentally ill patients, particularly patients with dementia. Two nurses from this primary care environment distributed a survey to collect information regarding nurses' attitudes toward people with dementia and designed a training education program to improve practice in dementia care. This study described the essentials needed to conduct this program in order to help nurses and help care providers in that setting to help mental health patients. Another study from Australia includes a descriptive study by Reed (2010) who investigated nurses' attitudes to caring for people with mental illness. The study questions focused on nurses' ability to provide care, the effect of education, experience, and general support. The study findings showed that nurses' attitudes link inextricably to issues that influence nurses' ability to provide care. Many nurses mentioned that it was not their role to care for mentally ill patients. However, nurses receiving additional specialized education described as to increase comfort and expressed enthusiasm for mental health care. They also described physical care, environmental unsuitability, rurality, and poor knowledge and training as barriers to providing effective care (Reed, 2010). Notably, collaboration with health care providers would help to increase competence in caring for people with mental illness.

Another study was conducted in UK by Murray and colleagues (2006) who examined general physicians, practitioners, nurses and counsellors who worked for more than one year in London regarding knowledge and attitudes toward elderly people with depression. General health care providers mentioned that elderly people rarely talked about psychological difficulties. Moreover, many elderly people believed that depression is a part of the aging process. Kapungwe and colleagues (2011) conducted a study of 111 patients to assess health care provider attitudes towards mentally ill patients in Zambia. The study was conducted so that results could inform the design of training programs in the primary health care settings. The results showed that there were significant discriminatory attitudes toward mentally ill patients and the reason of that is lacking of training.

Ndetei, Khasakhala, Mutiso, and Mbwayo (2011) aimed to determine attitudes and beliefs about mental illness among staff in general health care settings by using a descriptive cross sectional study. The results of the study show that from 684 general hospital staff: nurses (47.8\%); physicians (18.1\%); most of them believe that mental illnesses can be easily managed in the general health care setting like in health care centers. Most of these workers did not suspect any mental illness symptoms among the patients and provided low referral rates to specialty mental health facilities.

Adewuya, Abiodun and Oguntade (2007) aimed to determine the attitude of primary care providers in Nigeria. Almost 312 primary care providers from eight health care settings completed a survey about knowledge and attitudes about mental illnesses. The results showed a negative attitude toward mentally ill patients amongst $64.1 \%$. The factors related to this phenomena are having a family member/friend with mental illness (OR7.12, 95\% CI 3.71-13.65), being young (OR 2.33, 95\% CI 1.23-4.40), not having enough clinical experience (OR 6.75, 95\% CI 3.86-11.82) and female sex (OR 4.98, 95\% CI 2.70-9.18). The study by Hamaideh and Mudallal (2009) aimed to 
assess Jordanian Nursing students' attitudes towards mental illness and to evaluate the effectiveness of teaching and contact on change on their attitudes. Using the Opinion about Mental Illness (OMI) questionnaire, the reported results from 193 Jordanian students revealed that students positive attitudes toward mental illness were changed positively after taking the teaching course (Hamaideh \& Mudallal, 2009).

\subsection{Lack of Cooperation Between General Physicians and Psychiatrists}

Another reason that cause health care provider to hold stigma against mental health patiente is lack of cooperation between health care providers from different specialities. Beacham, Kinman, Harris, and Masters (2012) and McGrath and Sammons (2011), discussed the opportunities and challenges of providing mental health care in primary settings. The need for an evolution of mental health services in the primary care setting. They also suggested a need to adapt services to meet new demands by expanding treatment to also involve primary healthcare providers, instead of only psychiatrists. They also described the political and legal challenges for moving these services to primary health care settings (McGrath \& Sammons, 2011). This process required integration between psychologists and physicians to benefit the whole system and decrease mental health care service expenses. To study the collaboration between physicians and psychologists for peadiatric population, Drotar (1995) study describes problems pediatricians face in covering all pediatric population medical needs including services that are typically provided by psychologists. Drotar's study also documents that many pediatricians did not refer children with mental health problems to psychologists because of lack of cooperation to these services within primary care settings (Drotar, 1995). To solve this problem Haley (1998) suggests several ways to enhance collaborations between psychologists and physicians who tend to have very different perspectives on the needs of mental health patients. There is an urgent need to differentiate between these perspectives in primary care settings to satisfy patient mental health needs. However, there is an increase in treating mental health patients in primary care settings by primary care physicians.

\subsection{Lack of Exposure to Mental Ill Patients}

Lack of Exposing to mental ill patients is another reason may caurse health care provider to hold stigma against mental ill patines. Adams, Lee, Pritchard and White (2010) assessed UK primary health care providers attitudes toward patients with depression that affect them seeking health care. Almost 1488 primary practitioners completed a survey regarding attitudes toward these patients and causes of barriers to help seeking behavior. The results of this study showed that more than $50 \%$ of primary health care providers held stigmatizing views of depression. The stigmatization attitude was significantly reduced in those with a history of depression. Moreover, higher levels of perceived stigma from health care providers increased concerns about help-seeking (Adams, Lee, Pritchard, \& White, 2010). Efforts need to be made by the profession to reduce the negative behaviors toward patients. A more recent study, Niskanovic, Jelena; Siljak, and Sladana (2013) assessed attitudes towards people with mental illness among family medicine health care providers, and examined their attitudes regarding recruiting mentally ill patients. The result showed that stigma from health care providers prevents approximately $43 \%$ of mentally ill patients from seeking help at the time of disease. Also, attitudes toward people with mental disorders are positive among health care providers who have more exposure to mentally ill patients. Though European health care providers' attitudes toward mentally ill patients differ significantly across the country, the difference is related to wider social, cultural and organizational circumstances of health care practices.

\subsection{Consider Not Part of Job Duties}

Many health care provider hold a perception is not part of their job and it is duty for psychiatrist or psychologist. For example, Aldawi, Dorvlo, and Ismali (2002) compared the response from medical students and the general public of the attitudes toward mental ill patients. This study found that both medical students and the public have peculiar and stereotypical appearances toward mental ill patients. Moreover, and the majority preferred that facilities for psychiatric care should be located away from the community and the psychatris are responsible to help mental ill patients. In another study, Pidano et al. (2011), the author studied the comfort of pediatric primary care providers in diagnosing/assessing for and treating/managing mental health problems. The study found those primary pediatricians are comfortable assessing and diagnosing mental health problems, but not providing treatment. These health care providers are comfortable in assessing depression, ADHD, and anxiety disorders. On the contrary, they are not comfortable in assessing and diagnosing bipolar disorder, psychosis, posttraumatic shock, learning disorders and sexual abuse since they did not expose to many of these cases usually. Based on this study, it is more advantageous to refer mental health problems to psychologists for accurate diagnoses and treatments.

Certain mental health assessments are more recognized and common in general health care settings; an example is the routine screenings for depression. However, some researchers reported that these routine screenings are not helpful and can sometimes be harmful (Lowry, 2011). For example, some studies showed that screening for 
depression is only useful in helping patients with other health conditions that correlate with depression (Lowry, 2011). However, the use of depression treatment can help to inform the prognosis of a general medical condition, rather than serve as a basis for a psychological assessment.In Japan, Inagaki and colleagues (2013) explored the factors causing general physicians and other health care providers to consider dealing with depressed patients as not part of their duties.

Surveys regarding the perceived feasibility and willingness to treat depressed patients were distributed to these populations. The results of this study showed that general physicians were not willing to treat depressed patients as part of their practice. Moreover, few doctors referred depressed patients to psychiatrist. Another study conducted in India by Chowdhury and colleagues (2000) examined the indicators of stigma for mental illnesses among health care providers (HCPs) in rural areas. An adopted instrument from Bengali to assess stigma toward mentally ill patients was distributed to 34 general physicians. These health problems are depression, somatoform disorders, deliberate self-harm, psychosis, hysteria and possession. The results of this study showed that stigma is prevalent among general health care providers due to not consider dealing of mental ill patiens not part of their jobs. To conclude, certain mental health assessments are more recognized and common in general health care settings; an example is the routine screenings for depression and anxiety. Exposing to these conditions cause the health care providers to assess and treat them in usual.

\subsubsection{Implications of Mental Illness Stigma for Research and Ethics}

The Preceded information ascertained that stigma associated with mental illness have many ethical implications in the context of Responsible Conduct of research (RCR). These ethical implications can be seen in the form of issues related to consent form (Fisher \& Oransky, 2008; Vaz \& Srinivasan, 2014), fair treatment and good respect for individual rights concerning treatment choices (Carrier, Banayan, Boley, \& Karnik, 2017; Corcoran, 2016), use of various forms of treatments, participation in the clinical studies at the national level and issue of possible use of data for national or governmental purpose (Alahmad, Al-Jumah, \& Dierickx, 2012; Ayalon, Karkabi, Bleichman, Fleischmann, \& Goldfracht, 2015; Campbell et al., 2015; Sharma et al., 2013; Vaz \& Srinivasan, 2014). Indeed, scientific researchers and those who are conducting research studies about mental health in the primary health care settings (Dubois et al., 2011); must consider the applications of ethical standards as suggested by RCR with cautions.

Researchers should follow rules concerning use of consent forms and how it might vary according to the target population being studied, the setting or cultural context where the study taking place (Alahmad et al., 2012; Carrier et al., 2017; Chowdhury, 2016; Corcoran, 2016; Mittal, Dean, Mittal, \& Saks, 2015; Pires Marques, 2017; Sharma et al., 2013; Shen et al., 2017; Vaz \& Srinivasan, 2014). Literature noted different components for consent forms, however they all point to the one important piece of "providing enough and detailed information in order to get the consent".

Of the other ethical implications of mental health stigma for RCR in primary care settings is the accuracy of information gathered. Mental health related topics are considered of the "hot or sensitive" topics (Mittal VA. et al., 2015 ) and usually perceived with stigma;thus, denial or concealing of the actual concerns are the most common coping when disoclosing information. Individuals suffer from mental health stigma might find it easier to provide false information "ideal responses" and not disclosing the actual "stigmatized" feelings or concerns related to mental illness. To this, researchers should provide detailed information about study of interest, its aims and that information gathered is for the purpose of research and will not lead to any risks or threats. Emotional risks because of stigma can be dealt with by being well-trained in field of RCR and clinical studies, and paying full attentions to the ethical principles and cultural concerns encountered when conducting research studies in this field (Chowdhury, 2016; Mittal et al., 2015).

Mental health stigma as noted before existed in various cultural context s around the world. In order to fight stigma and thus intervene its ethical implications as for RCR, interventions in the form of awareness programs would be the best way to minimize and stop it. Knowing that mental health services are not fully covered or utilized in the primary health care centers yet, efforts are to be directed toward integrating mental health services in these centers. Training the health care providers (physicians, nurses, counselors, or family physicians) is a necessary. These training programs can be conducted in a regular basis to provide health care providers with necessary and needed information to enable them identify cases with mental health issues, provide suitable diagnosis and then provide right treatment or do referral to specialized psychiatrist.

\subsubsection{Implications of Mental Illness Stigma for Public Policy}

Stigma associated with mental illness tackled health care providers in primary health care settings requires 
intensive collaboration with governmental and public personnel. Researchers as well health care providers are to be familiar with ethics and standards for RCR. In searching for the available code of ethics or similar documents; Alhamad and Colleagues (2012) reviewed available national codes, regulations, and guidelines concerning research ethics, and 10 documents from eight countries -Jordan was included- were found (Alahmad et al., 2012). The results of this review showed that a lot of efforts have been made in many countries in the Middle East. Yet, in contrast with international documents, most of the research ethics documents in use in this region reveal numerous deficiencies. As it relates to these documents, extensive differences could be observed in regard to development, structure, content, and reference to international guidelines (Alahmad et al., 2012). Thus, efforts are to be gathered to initiate a regional or national code of ethics for RCR and more specifically for mental health research in the Arab Region and moe specifically- Jordan.

Further, efforts are to be made toward initiating specialized training program to provide care providers with needed knowledge and skills required to identify mental health problems, and thus identify those cases require specialized mental health care (Ayalon et al., 2015; Campbell et al., 2015; Chowdhury, 2016; Lally, O' Conghaile, Quigley, Bainbridge, \& McDonald, 2013; Pires Marques, 2017; Shen et al., 2017). Empowering primary health care providers will enable them to diagnose mental health problems at early stages, provide the required treatment and thus breack the barriers of stigma associated with mental illness. Having mental health services available at primary health care settings, and having care providers well trained and prepared to treat those in need for such specialized care will assure better identifications of cases, assure treatment with no risk of being discriminated or stigmatized. This will promote good health care and thus assure good quality of life.

In order for this initiative to succeed, public awareness campaigns and educational programs are to be initiated and ascertained (Lally et al., 2013). The impacts of stigma associated with mental illnesses among patients and health care provides can be minimized or even prevented once knowledge and skills necessary to treatment are made available. Political and governmental support in the forms of approving policies toward integrating mental health services in primary health care settings is an important step. Health care laws are to support such integration and plans are to be settled up to apply the changes required to maintain the health care of patients suffering from mental illness in primary health care settings.

\subsubsection{The Case of Jordan}

Jordan as one of the developing countries witnesses a lack of guidance on the ethics of conducting such research in affected populations with particular focus on mental health (Alahmad et al., 2012; Ngui, Khasakhala, Ndetei, \& Roberts, 2010). Despite the fact that Ethical Review Boards exist in many countries; additional safeguards are needed for refugees and internally displaced populations and when undertaking research in a humanitarian context.

Jordan has been a refugee hosting country for many years including large influxes of Iraqis and now Syrians, which requests to the Health Sector Working Group to conduct research studies, that are frequent and often based on the needs/interests of researchers and not on research gaps identified by operational agencies (Campbell et al., 2015; Kong, Dunn, \& Parker, 2017; Shen et al., 2017; Vaz \& Srinivasan, 2014). Furthermore, to date, there have been few measures beyond standard ethical review procedures to ensure that specific protection or ethical concerns relating to people with mental health problems or refugees are considered in planning and conducting and reporting research.

\section{Conclusion}

The major purpose of this study was to synthesize literature concerned the attitude of primary health care providers towards mentally ill patients. In this review, the causes of this attitude were related to a lack of knowledge, professional orientation, supervision status, and experience. The findings of this literature review support the positive effect of mental health training and experience on stigmatizing attitudes. This paper ascertained the importence of having an active Research Review Board concerns the application of ethical principles encountered when treating, doing research or practice in mental health care contexts. Further, there is a need to further develop the evidence base of the effects of mental health and wellbeing and the outcomes of programmatic interventions. Extensive work is needed to provide a rigorous assessment of the quality and depth of the evidence-base that informs public health programming at both national and global levels. Finally, ethical implications for mental health stigma were highlighted with special considerations about Jordan.

\section{Competing Interests Statement}

The authors declare that there are no competing or potential conflicts of interest. 


\section{References}

Abuhammad, S., Hatamleh, R., Howard, K., \& Ahmad, M. M. (2018). Correlates and predictors of stigmatization of patients with mental illness among nursing students. Journal of psychosocial nursing and mental health services, 57(1), 43-51.

Adams, E. F., Lee, A. J., Pritchard, C. W., \& White, R. J. (2010). What stops us from healing the healers: a survey of help-seeking behaviour, stigmatisation and depression within the medical profession. International Journal of Social Psychiatry, 56(4), 359-370. https://doi.org/10.1177/0020764008099123

Adewuya, A. O., \& Oguntade, A. A. (2007). Doctors' attitude towards people with mental illness in Western Nigeria. Social psychiatry and psychiatric epidemiology, 42(11), 931-936. https://doi.org/10.1007/s00127-007-0246-4

Al-Adawi, S., Dorvlo, A. S., Al-Ismaily, S. S., Al-Ghafry, D. A., Al-Noobi, B. Z., Al-Salmi, A., ... \& Chand, S. P. (2002). Perception of and attitude towards mental illness in Oman. International journal of social psychiatry, 48(4), 305-317. https://doi.org/10.1177/002076402128783334

Alahmad, G., Al-Jumah, M., \& Dierickx, K. (2012). Review of national research ethics regulations and guidelines in Middle Eastern Arab countries. BMC Medical Ethics, 13(34). https://doi.org/10.1186/1472-6939-13-34

Ayalon, L., Karkabi, K., Bleichman, I., Fleischmann, S., \& Goldfracht, M. (2015). Between modern and traditional values: Informal mental health help-seeking attitudes according to Israeli Arab women, primary care patients and their providers. The International Journal of Social Psychiatry, 61(4), 386-393. https://doi.org/10.1177/0020764014549082

Beacham, A. O., Kinman, C., Harris, J. G., \& Masters, K. S. (2012). The patient-centered medical home: Unprecedented workforce growth potential for professional psychology. Professional Psychology: Research and Practice, 43(1), 17. https://doi.org/10.1037/a0025320

Bell, J. S., Aaltonen, S. E., Airaksinen, M. S., Volmer, D., Gharat, M. S., Muceniece, R., ... \& Chen, T. F. (2010). Determinants of mental health stigma among pharmacy students in Australia, Belgium, Estonia, Finland, India and Latvia. International Journal of Social Psychiatry, 56(1), 3-14. https://doi.org/10.1177/0020764008097621

Blount, F. A., \& Miller, B. F. (2009). Addressing the workforce crisis in integrated primary care. Journal of Clinical Psychology in Medical Settings, 16(1), 113. https://doi.org/10.1007/s10880-008-9142-7

Bray, J. H. (2011). Training for the future of psychology practice. Training and Educationin Professional Psychology, 5(2), 69-72. https://doi.org/10.1037/a0023713

Brown, K., \& Bradley, L. J. (2002). Reducing the stigma of mental illness. Journal of Mental Health Counseling, 24(1), 81.

Campbell, M. M., Susser, E., De Vries, J., Baldinger, A., Sibeko, G., Mndini, M. M., et al. (2015). Exploring researchers' experiences of working with a researcher-driven, population-specific community advisory board in a South African schizophrenia genomics study. BMC Medical Ethics (1472-6939 (Electronic)). https://doi.org/10.1186/s12910-015-0037-5

Carrier, F., Banayan, D., Boley, R., \& Karnik, N. (2017). Ethical challenges in developing drugs for psychiatric disorders. Progress in neurobiology, May (1873-5118 (Electronic)). https://doi.org/10.1016/j.pneurobio.2017.03.002

Chambers, M., Guise, V., Välimäki, M., Botelho, M. A. R., Scott, A., Staniuliene, V., \& Zanotti, R. (2010). Nurses' attitudes to mental illness: A comparison of a sample of nurses from five European countries. International Journal of Nursing Studies, 47(3), 350-362. https://doi.org/10.1016/j.ijnurstu.2009.08.008

Chee, C. Y., Ng, T. P., \& Kua, E. H. (2005). Comparing the stigma of mental illness in a general hospital with a state mental hospital. Social Psychiatry and Psychiatric Epidemiology, 40(8), 648-653. https://doi.org/10.1007/s00127-005-0932-z

Chowdhury, A. N., Sanyal, D., Dutta, S. K., Banerjee, S., De, R., Bhattacharya, K., ... \& Weiss, M. G. (2000). Stigma and mental illness: Pilot study of laypersons and health care provides with the EMIC in rural West Bengal, India. International Medical Journal-Tokyo, 7(4), 257.

Chowdhury, N. (2016). Integration Between Mental Health-Care Providers and Traditional Spiritual Healers: Contextualising Islam in the Twenty-First Century. Journal of Religion and Health, 55(5), 1665-1671. 
https://doi.org/10.1007/s10943-016-0234-7

Corcoran, C. M. (2016). Ethical and Epidemiological Dimensions of Labeling Psychosis Risk. AMA Journal of Ethics, 18(6), 633-642. https://doi.org/10.1001/journalofethics.2016.18.6.msoc2-1606

Corrigan, P. (2004). How stigma interferes with mental health care. The American Psychologist, 95(7), 614-625. https://doi.org/10.1037/0003-066X.59.7.614

Corrigan, P. W., \& Miller, F. E. (2004). Shame, blame, and contamination: A review of the impact of mental illness stigma on family members. Journal of Mental Health, 13(6), 537-548. https://doi.org/10.1080/09638230400017004

Corrigan, P. W., Watson, A. C., \& Miller, F. E. (2006). Blame, shame, and contamination: The impact of mental illness and drug dependence stigma on family members. Journal of Family Psychology, 20(2), 239-246. https://doi.org/10.1037/0893-3200.20.2.239

Crabtree, J., \& Mack, J. (2010). Designing a training programme to improve staff attitudes towards people with dementia. Nursing times, 106(39), 14-16.

Dalky, H. F. (2012a). Mental illness stigma reduction interventions: review of intervention trials. Western Journal of Nursing Research, 34(4), 520-547.

Dalky, H. F. (2012b). Perception and coping with stigma of mental illness: Arab families' perspectives. Issues in Mental Health Nursing, 33(7), 486-491.

Drotar, D. (1995). Consulting with pediatricians. Springer Science \& Business Media.

Dubois, J., Bailey-Burch, B., Bustillos, D., Campbell, J., Cottler, L., Fisher, C., et al. (2011). Ethical issues in mental health research: the case for community engagement. Current Opinion in Psychiatry, 24(3), 208-214. https://doi.org/10.1097/YCO.0b013e3283459422

Filipčić, I., Pavičić, D., Filipčić, A., Hotujac, L., Begić, D., Grubišin, J., \& Đorđević, V. (2003). Attitudes of Medical Staff Towards the Psychiatric Label» Schizophrenic Patient «Tested by an Anti-Stigma Questionnaire. Collegium antropologicum, 27(1), 301-307.

Fisher, C. B., \& Oransky, M. (2008). Informed consent to psychotherapy: protecting the dignity and respecting the autonomy of patients. Journal of Clinical Psychology, 64(5), 576-588. https://doi.org/10.1002/jclp.20472

Goffman, E. (1963). Stigma: Notes on the Management of Spoiled Identity. New York: Prentice Hall.

Haley, W. E., McDaniel, S. H., Bray, J. H., Frank, R. G., Heldring, M., Johnson, S. B., .. Wiggins, J. G. (1998). Psychological practice in primary care settings: Practicaltips for clinicians. Professional Psychology: Research and Practice, 29, 237-244. https://doi.org/10.1037/0735-7028.29.3.237

Hamaideh, S., \& Mudallal, R. (2009). Attitudes of Jordanian Nursing Students towards Mental Illness: The Effect of Teaching and Contact on Attitudes Change. College Student Journal, 43(2), 335-346.

Hamdan-Mansour, A. M., \& Wardam, L. A. (2009). Attitudes of Jordanian mental health nurses toward mental illness and patients with mental illness. Issues in Mental Health Nursing, 30(11), 705-711. https://doi.org/10.1080/01612840903131792

Inagaki, M., Ohtsuki, T., Ishikura, F., Kodaka, M., Watanabe, Y., \& Yamada, M. (2013). Factors Associated with Perceived Feasibility and Willingness of Non-Psychiatric Doctors in Japan to Treat Depressed Patients. The International Journal of Psychiatry in Medicine, 46(2), 153-167. https://doi.org/10.2190/PM.46.2.c

Kapungwe, A., Mwanza, J., Mwape, L., Sikwese, A., Cooper, S., Lund, C., \& Mayeya, J. (2011). Attitudes of primary health care providers towards people with mental illness: evidence from two districts in Zambia: original. African Journal of Psychiatry, 14(4), 290-297. https://doi.org/10.4314/ajpsy.v14i4.6

Kessler, R. C., Chiu, W. T., Demler, O., \& Walters, E. E. (2005). Prevalence, severity, and comorbidity of twelve-month DSM-IV disorders in the National Comorbidity Survey Replication (NCS-R). Archives of General Psychiatry, 62(6), 617-627. https://doi.org/10.1001/archpsyc.62.6.617

Kong, C., Dunn, M., \& Parker, M. (2017). Psychiatric Genomics and Mental Health Treatment: Setting the Ethical Agenda. American Journal of Bioethics, 17(4), 3-12. https://doi.org/10.1080/15265161.2017.1284915

Kravitz, R. L., Franks, P., Feldman, M., Meredith, L. S., Hinton, L., Franz, C., .. Epstein, R. M. (2006). What drives referral from primary care physicians to mental health specialists? A randomized trial using actors portraying depressive symptoms. Journal of General Internal Medicine, 21, 584-589. 
https://doi.org/10.1111/j.1525-1497.2006.00411.x

Lally, J., O' Conghaile, A., Quigley, S., Bainbridge, E., \& McDonald, C. (2013). Stigma of mental illness and help-seeking intention in university students. The Psychiatrist, 37(8), 253-260. https://doi.org/10.1192/pb.bp.112.041483

Link, B. G., \& Phelan, J. C. (2001). Conceptualizing stigma. Annual Review of Sociology, 27, 363-385. https://doi.org/10.1146/annurev.soc.27.1.363

Major, B., \& O'Brien, L. (2005). The social psychology of stigma. Annual Review of Psychology, 56, 393-421. https://doi.org/10.1146/annurev.psych.56.091103.070137

McGrath, R. E., \& Sammons, M. (2011). Prescribing and primary care psychology: Complementary paths for professional psychology. Professional Psychology: Research and Practice, 42(2), 113-260. https://doi.org/10.1037/a0022649

Miller, A.R., Johnston, C., Klassen, A.F., Fine, S., \& Papsdorf, M. (2005). Family physicians' involvement and self-reported comfort and skill in care of childrenwith behavioral and emotional problems: A population-based survey. BMC Family Practice, 6(12). https://doi.org/10.1186/1471-2296-6-12

Miller, P.J. (2009). Personality as a potential moderator of the relationship betweenstigma and help-seeking (Doctoral dissertation). Retrieved from ProQuestDissertations and Theses - Full Text. (UMI No. 3369865)

Mishra, N. N., Bhatia, T., Kumar, N., Nimgaonkar, V. L., Parker, L. S., \& Deshpande, S. N. (2014). Knowledge \& attitudes of mental health professionals regarding psychiatric research. The Indian Journal of Medical Research, 139(2), 246-251.

Mittal, V. A., Dean, D. J., Mittal, J. F., \& Saks, E. R. (2015). Ethical, Legal, and Clinical Considerations when Disclosing a High-Risk Syndrome for Psychosis. Bioethics, 29(8), 543-556. https://doi.org/10.1111/bioe.12155

Ndetei, D. M., Khasakhala, L. I., Mutiso, V., \& Mbwayo, A. W. (2011). Knowledge, attitude and practice (KAP) of mental illness among staff in general medical facilities in Kenya: practice and policy implications. African journal of psychiatry, 14(3), 225-235. https://doi.org/10.4314/ajpsy.v14i3.6

Ngui, E. M., Khasakhala, L., Ndetei, D., \& Roberts, L. W. (2010). Mental disorders, health inequalities and ethics: A global perspective. International review of psychiatry, 22(3), 235-244. https://doi.org/10.3109/09540261.2010.485273

Pidano, A. E., Kimmelblatt, C. A., \& Neace, W. P. (2011). Behavioral health in thepediatric primary care setting: Needs, barriers, and implications for psychologists. Psychological Services, 8(3), 151-165. https://doi.org/10.1037/a0019535

Pires Marques, T. (2017). Global mental health, autonomy and medical paternalism: reconstructing the 'French ethical tradition' in psychiatry. History of Psychiatry, 28(3), 326-343. https://doi.org/10.1177/0957154X17706475

Purves, D., \& Sands, N. (2009). Crisis and triage clinicians' attitudes toward working with people with personality disorder. Perspectives in psychiatric care, 45(3), 208-215. https://doi.org/10.1111/j.1744-6163.2009.00223.x

Rayan, A., \& Jaradat, A. (2016). Stigma of Mental Illness and Attitudes Toward Psychological Help-seeking in Jordanian University Students. Research in Psychology and Behavioral Sciences, 4(1), 7-14.

Reed, F., \& Fitzgerald, L. (2005). The mixed attitudes of nurse's to caring for people with mental illness in a rural general hospital. International Journal of Mental Health Nursing, 14(4), 249-257. https://doi.org/10.1111/j.1440-0979.2005.00389.x

Sartorius, N. (2012). Guidance on how to combat stigmatization of psychiatry and psychiatrists. World Psychiatry, 11(1), 61-62. https://doi.org/10.1016/j.wpsyc.2012.01.014

Sartorius, N., \& Schulze, H. (2005). Reducing the Stigma of Mental Illness: A Report from a Global Association (1st ed.). New York: Cambridge University Press. https://doi.org/10.1017/CBO9780511544255

Shahrour, T. M., \& Rehmani, R. S. (2009). Testing psychiatric stigma in a general hospital in Saudi Arabia. Saudi medical journal, 30(10), 1336-1339.

Sharma, V., Durrani, S., Sawa, M., Copeland, J., Abou-Saleh, M., Lane, S., et al. (2013). Arabic version of the Global Mental Health Assessment Tool-Primary Care version (GMHAT/PC): a validity and feasibility study. Eastern Mediterranean Health Journal, 19(11), 905-908. https://doi.org/10.26719/2013.19.11.905 
Shen, N., Sockalingam, S., Abi Jaoude, A., Bailey, S. M., Bernier, T. r. s., Freeland, A., et al. (2017). Scoping review protocol: education initiatives for medical psychiatry collaborative care. BMJ Open, 7(9). https://doi.org/10.1136/bmjopen-2017-015886

Vaz, M., \& Srinivasan, K. (2014). Ethical challenges \& dilemmas for medical health professionals doing psychiatric research. The Indian Journal of Medical Research, 139(2), 191-193.

World Health Organization [WHO]. (2001). The world health report 2001 - Mental Health: New Understanding, New Hope. Retreived online from http://www.who.int/whr/2001/en/

Worrall, G., Angel, J., Chaulk, P., Clarke, C., \& Robbins, M. (1999). Effectiveness of aneducational strategy to improve family physicians' detection and management ofdepression: A randomized controlled trial. Canadian Medical AssociationJournal, 161, 37-40.

\section{Copyrights}

Copyright for this article is retained by the author(s), with first publication rights granted to the journal.

This is an open-access article distributed under the terms and conditions of the Creative Commons Attribution license (http://creativecommons.org/licenses/by/4.0/). 